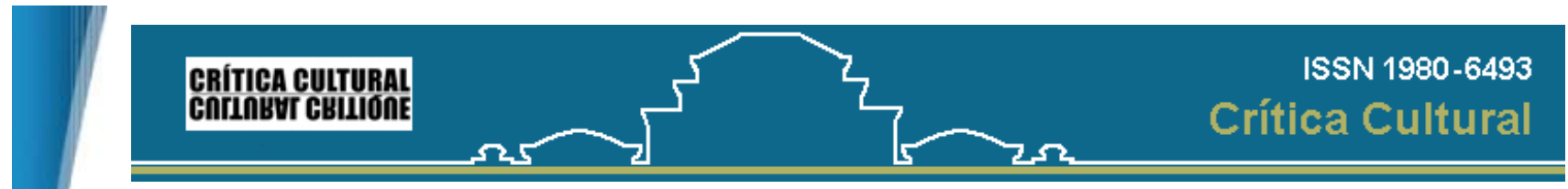

Crítica Cultural, volume 2, número 1, jul./dez. 2007

\title{
VIDAS SIN HISTORIAS. PARA UNA SEMIÓTICA DEL AUTORRETRATO LITERARIO
}

\author{
Luz Rodríguez Carranza*
}

Resumen: Este trabajo propone una reflexión sobre ciertos textos que comparten muchas de las características de los retratos; su nombre moderno es el de "autorretrato literario". Se trata de un género muy antiguo, ignorado y marginalizado - o incluido indiscriminadamente entre los ensayos - por las poéticas modernas, que consideran Las confesiones de Rousseau como punto de partida absoluto de las escrituras del yo. Para describir su manera peculiar de comunicar, confrontamos aquí los "autorretratos" con algunos conceptos de la filosofía de la imagen (Jean Luc Nancy) y la semiótica (Umberto Eco).

Palabras-clave: vida literaria; huellas; voz; memoria; autobiografía.

\section{Vidas}

La expresión "Vida literaria" proviene del formalismo ruso, y es utilizada " para designar globalmente el contexto material y cultural o la infraestructura en los que las obras literarias son escritas, distribuidas y recibidas » (VAN GORP e.a., 255). En ese contexto los escritores son figuras imprescindibles: hay que mostrarlos, y las vidas literarias - en plural - son las vidas de los que escriben literatura. Presentaciones de libros, entrevistas, biografías o autobiografías no tienen solamente la función de explicar, interpretar y clasificar, como la crítica literaria, sino sobre todo la de de satisfacer a lectores que, como dice John Updike,

\begin{abstract}
leemos, quienes lo hacemos, biografías literarias por una diversidad de razones, entre las cuales la primera, y tal vez la más importante, es el deseo de prolongar e intensificar nuestra intimidad con el autor - volver a disfrutar, desde otro ángulo, de las delicias que experimentamos dentro de la obra del autor, en presencia de una voz y una mente que llegamos a amar - . Un ejemplo de este tipo de prolongación es la maravillosa biografía de dos volúmenes de Marcel Proust escrita por George D. Painter, que leí de joven al poco tiempo de terminar En busca del tiempo perdido, intoxicado y sediento de más. [...] Los amantes de Proust inevitablemente se sentirán atraídos hacia Painter, precisamente porque es más de lo mismo [...].
\end{abstract}

Updike habla de una voz y de intimidad y eso es también lo que vende una editorial española, de acuerdo a su publicidad en Internet. [1] La editorial Omega se especializa en libros científicos y técnicos y tiene un catálogo que parece la clasificación de los animales de la Enciclopedia China de «El idioma analítico de John Wilkins» de Borges, porque lo que más llama la atención es la cantidad de categorías que refieren a seres vivos: Botánica, Fisiología Vegetal, Aves, Peces, Moluscos, Animales domésticos, etc. La literatura es pobre en el catálogo, pero están presentes esas raras formas de vida que son los escritores: hay una colección de «Vidas Literarias», que reúne ya varios nombres célebres, presentados a su vez por otros escritores. Algunos ejemplos: Fernando Savater sobre Jorge Luis Borges, Cristina Peri Rossi sobre Julio Cortázar, César Aira sobre Alejandra Pizarnik. Un éxito editorial - a juzgar por la aparición de nuevos títulos - que no es ajeno a su propósito antihermenéutico: lo que publican «no es la biografía ni el ensayo académico sobre un autor y su obra, sino su recreación literaria, personal, a cargo de otro escritor». [2] Lo que rehusan, la biografía o el ensayo, son precisamente las dos modalidades de la puesta en discurso: la narración y la argumentación. Que lo logren o no no es lo que me interesa aquí - muchas reseñas sobre las obras de la colección las consideran biografías sino la promesa de un contacto sin mediaciones interpretativas, prerrogativa de las imágenes, y más particularmente de los retratos.

En este trabajo me propongo reflexionar sobre ciertos textos que comparten muchas de las características de los retratos: de hecho, su nombre moderno es el de "autorretrato literario" (Beaujour). Se trata de un género muy antiguo, ignorado y marginalizado - 0 incluido indiscriminadamente entre los ensayos - por las poéticas modernas, que siguen considerando Las confesiones de Rousseau como punto de partida absoluto de las escrituras del yo. Los "autorretratos" proliferan sin embargo, y para describir su manera peculiar de comunicar voy a confrontarlos aquí con algunos conceptos de las dos disciplinas que me permitieron comprenderlos: la filosofía de la imagen (Nancy) y la semiótica (Eco). [3]

\section{Huellas}

Lo que se reconoce de un escritor en sus textos, lo que se quiere volver a experimentar es una voz, y lo que quieren evitar muchos lectores - como lo sabe la editorial Omega - es que esa voz se encuentre prisionera de un discurso, de un lenguaje. La distinción entre voz y lenguaje es muy relevante cuando se trata de conocer vidas, porque separa la vida desnuda, propia de todos los seres vivientes (la zoé de los griegos) de la bios, la inclusión y el control de la vida natural por el estado, la biopolítica de Foucault (La volonté de savoir, 183). «El nexo entre nuda vida y política es el mismo que la definición metafísica del hombre como 'viviente que posee el lenguaje' busca en la articulación entre phõné y logos», explica Agamben citando a Aristóteles:

\begin{abstract}
Sólo el hombre, entre los vivientes, posee el lenguaje. La voz es signo del dolor y del placer, y, por eso, la tienen también el resto de los vivientes (su naturaleza ha llegado, en efecto, hasta la sensación del dolor y del placer y a transmitírsela unos a otros); pero el lenguaje existe para manifestar lo conveniente y lo inconveniente, as como lo justo y lo injusto. Y es propio de los hombres, con respecto a los demas vivientes, el tener sólo ellos el sentido del bien y del mal, de lo justo y de lo injusto y de las demás cosas del mismo género, y la comunidad de estas cosas es la que constituye la casa y la ciudad (Política, 1253a, 10-18 en AGAMBEN, 17)
\end{abstract}

Ahora bien, a diferencia de la simple zoé esta voz se muestra expresamente en algunos textos. En eso coincide con la manera de ser de las imágenes, tal como las describe Jean-Luc Nancy, que no sólo están separadas, sino que marcan esa separación, recortándose contra un fondo que nos obliga a verlas: no están «excluídas en su inclusión», como la vida marginalizada por la biopolítica, sino que llaman la atención precisamente por su aislamiento:

Lo distinto se distingue: se pone al margen, marca por lo tanto ese margen y lo hace notar - se hace notar. Llama también la atención: en su retiro y desde ese retiro hay un atractivo, una atracción (en su doble sentido de fuerza que atrae y de seducción). La imagen es deseable o no es imagen» (Au fond des images, 20).

Es un contacto que no se propone nada: la imagen es pasiva, y su poder proviene precisamente de la pasividad, domina ofreciéndose, desestabilizando toda dialéctica de amo y esclavo $\frac{[4]}{\text { y }}$ está fuera del sentido y del discurso («sens en discours, sens qui a cours», Au fond des images, 27). La hermenéutica, en cambio, ocupa activamente la distancia con la interpretación. La imagen es vista, la hermenéutica ve y ejerce la biopolítica clasificatoria: «una distribución determinada y concertada de los cuerpos, de las superficies, de las luces, de las miradas; en un aparato cuyos mecanismos internos producen las relaciones en las que son atrapados los individuos» (FOUCAULT, Surveiller et Punir, 203). 
Las huellas no son signos. Según Peirce, un signo es algo que está, para alguien, en lugar de algo, en algún sentido o capacidad (2.288). El signo icónico representa su objeto por semejanza o analogía - una estructura perceptiva semejante - según una determinada correlación cultural (ECO, signe iconique, 152-153). El signo indicial, a su vez, es aquel que está o ha estado en contacto con su objeto: las huellas o los síntomas como el humo (signo) y el fuego (objeto) son los casos más característicos. Ahora bien, los indicios no son signos sino testimonios de una presencia, a menos que estén integrados en una función semiótica de reconocimiento. Las huellas, en particular, son testimonios paradójicos ya que, como los signos, remiten a la ausencia del objeto que las imprimió: la diferencia es que no están en su lugar, ni tampoco son copias ni reflejos, sino la marca de algunos rasgos del agente. Esos rasgos no se distinguían antes de la existencia de la huella, sino que es en ella que están presentes y ex-puestos, vale decir, puestos afuera. Son rastros de movimiento, no una máscara mortuoria, sino una ninfa: el capullo de seda que, incluso destrozado, guarda las huellas de las alas y de la metamorfosis de la mariposa. No hay, obviamente, representación: «la imagen no tiene modelo, sino que su modelo está en ella» (NANCY, Au fond des images, 25). La semiótica había llegado a fines de los años ' 90 a las mismas conclusiones que la filosofía e incluso más lejos, sugiriendo la posibilidad de un modelo - código o interpretante - futuro y retroactivo. Umberto Eco aceptó la existencia de un iconismo primario no codificado, el «umbral inferior de la semiótica»:

la calidad propia de huellas que no han encontrado todavía (necesariamente) su objeto impresor, pero que están listas para «reconocer» ese objeto. [...] pura ausencia, imagen de algo que todavía no es. Parecería que este ícono primario sería algo así como un agujero [..] que pudiera sólo ser reconocido como una falta al interior de algo que sí está presente» (Kant, 153, el subrayado es mío). [5]

\section{Retratos}

La voz de un escritor, como la imagen, es una huella: algunos rasgos adquieren forma en sus obras, el objeto impresor es desconocido, y la interpretación no está codificada. "¿Qué hechos de su vida pueden explicar su obra?» es la pregunta incesante de muchos lectores y entrevistadores televisivos, e incluso de algunos profesores de literatura. En algunos casos la pregunta está motivada por la necesidad imperiosa de controlar la falta, de llenar la distancia con relatos identitarios o parábolas edificantes: los escritores mismos colaboran fecuentemente con ese control. Nada más extraño que la imagen de sí mismo, «el resultado de ese momento sutil en el que no soy ni sujeto ni objeto» (BARTHES, 30), y lo mismo pasa con la voz, con el grito de dolor o de placer. La reacción autobiográfica es defensiva. Es necesario, rápidamente, conjurar el movimiento amenazador que está allí, el de esa vida nuestra exterior y extraña que escuchamos o vemos, y convertirlo en el otro movimiento, el conocido y tranquilizador de la subjetividad. A veces, sin embargo, la pregunta en cuestión o la respuesta no buscan la interpretación normalizadora, ni establecer relaciones de causa a efecto entre acontecimientos y «versiones» literarias. Lo que se pide y/o lo que se da no es un «quién» sino un «qué»: más de lo mismo, en palabras de Updike, «más de esa voz y esa mente que llegamos a amar». Lo que se pide es que aparezca otra vez una presencia inconfundible: se pide un retrato, «una persona considerada en ella misma» (NANCY, Le regard, 11). Ahora bien, los escritores son «ellos mismos» escribiendo, y es en lo que escriben donde se encuentra su huella, en el momento en que la voz se convierte en lenguaje. El retrato da testimonio de esa metamorfosis (ANTELO).

La resistencia o moldeabilidad de la materia receptora es, como en la huella, indisociable del retrato: el soporte no es sólo una superficie lisa, una tabula rasa, sino que está formado ya. En el caso de la imagen, la pictórica por ejemplo, «es un error creer que el pintor está delante de una superficie blanca [..] debe vaciar, despejar, limpiar. No pinta para reproducir sobre la tela un objeto funcionando como modelo, pinta sobre imágenes que ya están allí» (DELEUZE, 57). Lo mismo opina la semiótica:

El retrato incorpora diversos tipos de actividad productiva e ilustra prácticamente toda la actividad semiótica. Es un acto referencial porque propone, a partir de estimulaciones programadas, el equivalente de una percepción [...] Es una invención, porque el modelo perceptivo no existe previamente [...] Absolutamente in-codificado, se apoya sobre muchos rasgos ya codificados, y la invención es aceptada a causa de la presencia de huellas, de estilizaciones, de ejemplos, de unidades seudo-combinatorias, de vectores, que están todos todos codificados. Es un texto complejo cuyo contenido va de una unidad codificada e identificable (el señor Fulano) hasta enunciados prácticamente infinitos y a una nebulosa de contenido. Pero en la medida en que es reconocido y registrado por una cultura, crea su propio 'tipo' (pero en el sentido de 'tipo' que no difiere mucho del concepto semiótico) el Héroe, el Gentilhombre, estilizaciones ulteriores que tuvieron a la invención como modelo. (ECO, signo icónico, 190). [6]

En el caso de la voz más que pintar sobre, se trata de pintar con, porque esas formas preexistentes - ya codificadas como lo explica Eco - no pueden ser ignoradas. Un escritor está hecho de discursos, mal que le pese a la editorial Omega. Desde Foucault sabemos que el relato de una vida es permeable a las palabras que se utilizan para contarla, y que las historias que «salen» como interioridad ordenada son lo más ajeno: las normas y valores que nos marcaron, que dejaron huellas en nosotros: "el 'yo hablo' funciona a contramano del 'yo pienso'. Este conducía a la certeza indudable del Yo y de su existencia; aquel, al contrario, retrocede, dispersa, borra esa existencia y no deja aparecer más que su lugar vacío» (La pensée du dehors, 548).

Este es el punto de partida consciente de textos en primera persona que no esperaron la muerte del sujeto para manifestarse $\frac{[7]}{\text { y que }}$ obsesionaron a Philippe Lejeune, quien los bautizó "autorretratos" porque no narran: es el caso de los Ensayos de Montaigne. En una advertencia al lector, Montaigne informa que se ha propuesto «pintarse» a sí mismo, pero, afirma Lejeune, «no hay relato continuado, ni historia sistemática de la personalidad. Autorretrato más que autobiografía» (57, el subrayado es mío). J erôme Cardan (1501-1551), científico y erudito, publicó una obra a la que llamó Vida (Vita, 1643) que según Lejeune es un fracaso, ya que «su libro no es un relato continuado sino una especie de bricolaje torpe, montaje poco coherente de una cincuentena de pequeños ensayos heteróclitos: yuxtapuso, simplemente, aplicándolos a su propia persona, todos los tipos de discursos que conocía» (56). Los ejemplos se multiplican, porque las «autobiografías» que más le obsesionan a Lejeune son precisamente aquellas que, como los «fracasos» de Montaigne y Cardan, son textos personales no cronológicos: las Rêveries de Rousseau (a diferencia de sus Confessions), el Ecce Homo de Nietzsche o los textos de Michel Leiris (1975).

Son textos inclasificables. No son autobiográficos, pero tampoco se trata de ensayos, porque no son argumentativos: no son «vidas ejemplares», no tienen ninguna utilidad ni se proponen nada. No son tampoco simples descripciones porque no importan los objetos, sino darse a conocer y descubrirse a sí mismo a través de ellos: «son mis fantasías» - escribe Montaigne - «por las cuales no intento dar a conocer las cosas, sino a mí» (Essais, II, x, 389). Michel Leiris parece aún más arrogante:

Me resulta siempre más difícil que a cualquiera expresarme de otro modo que con el pronombre YO; no porque haya que ver en ello algún signo particular de mi orgullo, sino porque esa palabra Yo resume para mí la estructura del mundo. Es sólo en función de mí mismo y porque me digno prestar alguna atención a su existencia que las cosas son (Aurora, 39).

Hay en los autorretratos una total ausencia de sentido, no son sentido-en curso pero, como lo señala Lejeune en su crítica a Cerdan, esa ausencia es de hecho una proliferación sin límites: yuxtaposición de todos los tipos de discursos que conoce el escritor. Conocer está aquí por recordar. se trata de aquellos discursos que han llamado su atención, lo han marcado, le han dejado su huella y lo han hecho quien es en el momento de escribir. Michel Beaujour recuerda una frase de San Agustín en sus Confesiones: «no voy a decirles lo que hice, voy a decirles quién soy» (9). Esta frase se encuentra al final del capítulo 3 del libro X, y en ese texto San Agustín medita sobre «la memoria, sobre el olvido y sobre la memoria del olvido, pero [... no dice nada sobre sí mismo» (9). Lo que sucede, dice Beaujour, es que si bien la experiencia inaugural del autorretratista es el vacío, apenas empieza a escribir,

ve esa nada transformarse en plétora [...] no sabe jamás claramente dónde va o lo que hace. Pero su tradición cultural lo sabe por él: y es ella que le proporciona las categorías hechas que le permiten ventilar las migas de su discurso, de recuerdos y de fantasmas. (10).

Las «categorías hechas» son los «rasgos ya codificados» que dibujan la «nebulosa de contenido» del retrato (Eco). Son la memoria del escritor, mucho más ambiciosa y al mismo tiempo mucho más humilde que la de la ilusión autobiográfica, porque sabe que es ajena. En los autorretratos literarios no hay cronología, sino yuxtaposición topológica de las huellas de las cosas - los recuerdos - en un rompecabezas en el que las piezas «se encuentran» y se engarzan entre ellas. Como lo adelanté en mi introducción, el género es muy antiguo: es el teatro de la memoria (RODRÍGUEZ CARRANZA, 254 ssg.) $\frac{[8]}{6}$ con raíces en el Ars Memorativa clásica, que a partir del Renacimiento fue integrado en el 


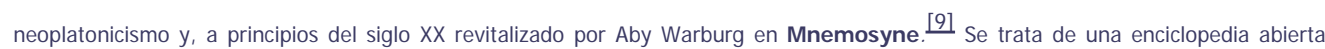
cuyo modelo es el del Ad Herennium - parte de un manual de retórica - y su esquema básico es el de locus ordenados según una imagen tópica (árbol, casa, jardín) $\underline{[10]}$ en los cuales se destacan imágenes. Ahora bien, San Agustín hace una distinción suplementaria en el capítulo X de las Confesiones: las cosas están en las grutas de la memoria presentes en imágenes, como todos los cuerpos, pero las artes, en cambio, están presentes en sí mismas (YATES, 59 ; RODRÍGUEZ CARRANZA, 256). En la memoria del escritor, los que están presentes son los discursos que lo marcaron: sus lecturas.

\section{Ecce Homo}

Tanto el (auto)retrato pictórico como el literario son huellas de aquello que ha marcado al artista, pero hay una diferencia semiótica entre ellos que me parece radical. El (auto)retrato pictórico es heteromaterial: la materia en la que se forman los trazos tiene otra consistencia y es diferente de la del agente impresor. En el caso del (auto)retrato literario, en cambio, las marcas son homomateriales y es comprensible la frustración de Lejeune - o la de cualquier narratólogo - ante una voz en primera persona que no siempre identifica el yo de la enunciación con el de los enunciados. Como en la sicastenia, es muy difícil percibir la diferencia, pero ésta existe, como lo descubren muy a su pesar las víctimas de la manta religiosa. La sicastenia no es solamente «la despersonalización por asimilación al espacio» como afirma Caillois (131). También es sicastenia el autoengaño frente al señuelo, la seducción que se muestra exageradamente como tal, una «super apariencia» más fuerte que la estimulación natural, un artificio al cual, incluso sabiendo que lo es - o precisamente por eso - no es posible resistir. Boris Cyrulnik lo explica con dos gorriones:

El macho empezaba a picotear las migas de mi croissant cuando la hembra se posó cerca suyo. Encogió el cuello, emitió pequeños gritos agudos y abrió un gran pico. Esta postura pedigüeña infantil provocó en el macho un comportamiento de alimentación. Y cuando, satisfecha, ella voló lejos, ya no había nada que picotear, porque el encanto de la hembra infantil había sido superior a la attracción de mi croissant (188-189).

La seducción artificiosa del señuelo tiene un efecto mucho más poderoso que el estímulo natural, por un lado porque activa la memoria: está compuesta de huellas, es la quintaesencia, la exageración de aquello que ha provocado un efecto. Por otro lado, su poder proviene precisamente de su exhibición: lo que desarma y seduce al gorrión es el deseo de la gorriona ejecutado para él en el rito infanti exagerado - que obviamente no le corresponde a ella sino a los pichones. No es casual que las únicas funciones semióticas en la clasificación de Eco que son homomateriales son las ostensivas, las que presentan un objeto o un acontecimiento seleccionándolo y designándolo para expresar la clase de objetos de la cual es miembro (signo icónico, 172). Las modalidades de ostensión son a) el ejemplo (la sinécdoque, un miembro por toda la clase), b) la muestra (pars pro toto) y c) las onomatopeyas. Aunque Eco las clasifique separadamente, sin embargo, también pueden ser ostensivas las réplicas de unidades combinatorias, como los símbolos, los emblemas y - lo que me interesa aquí - las estilizaciones.

Las estilizaciones son invenciones que han comunicado y podrían comunicar un discurso complejo, pero que se han vuelto simples y «revisten la función de 'nombres propios'» (175). Los ejemplos de estilización que da Eco son las figuras de los juegos de cartas, las del tarot, las del ajedrez, las imágenes religiosas; yo agregaría los estereotipos en general, los clichés, las figuras y los géneros: «Si ciertas propiedades han sido respetadas, establecemos una relación inmediata entre la expresión y su contenido convencional» (175). Los «nombres» de las lecturas de escritor que han dejado huellas en él - estilizaciones de discursos, figuras y géneros - afluyen inevitablemente en el momento de escribir: el autorretratista es consciente de ello y los ex-pone.

Ahora bien, la única manera de distinguir las cicatrices es conservarles su diferencia, sin suturas: presentarlas en relieve aficharlas separadas de toda «normalización» o ilusión referen origen» 0 actual, evitando la «inclusión exclusiva» del discurso. Como en las imágenes, lo que se retrata es el lugar vacío de la huella, mostrando, simultáneamente, el vaciamiento cóncavo que causa la voz en el lenguaje y el extrañamiento del lenguaje amoldándose a la voz. El autorretrato, dice Beaujour, «es un tipo de discurso que anticipa su texto desnudando - o dramatizando deliberadamente - los procedimientos dialécticos y las operaciones semánticas y linguísticas que lo engendran. El autorretrato se constituye mostrando su juego» (16) Así, la estilización es cita y yuxtaposición de citas que nombran una «nebulosa»: la vida.

Esto parece una promesa perversa si se considera que las estilizaciones son utilizadas como muestras, vale decir, pars-pro-toto de una

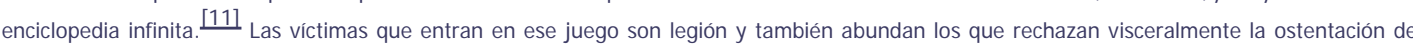
una erudición «elitista» y «narcisista» que «no sirve para nada». Efectivamente, nada es más ocioso o más inútil que un autorretrato, que no sólo no es transitivo - no persuade, no convence, no disuade ni explica - sino que pervierte toda ilusión comunicativa: sólo seduce mostrando, con lo que no es, su propio deseo y el que provoca en el espectador/lector. No ejerce la perversidad controladora ni el narcisismo autobiográfico porque ni es acción sobre otro ni es solipsismo, sino «la pasión - a la vez más pasiva y más activa - de una relación con el otro en sí, o consigo como otro» (NANCY, Le regard, 45). Lo que seduce o lo que repugna en estos textos es su entrega sin control: un goce desaforado e impúdico, que arrastra al lector hasta que le contagia el goce y no le queda más remedio que mostrarlo a su vez: escribir.

El autorretrato no sirve para nada, pero inútil no es sinónimo de frívolo, sino de testimonio. Es el momento de la verdad (AGAMBEN en ANTELO); es hablar del (no) yo sin dar un grito.

Un hombre se propone la tarea de dibujar el mundo. A lo largo de los años puebla un espacio con imágenes de provincias, de reinos, de montañas, de bahías, de naves, de islas, de peces, de habitaciones, de instrumentos, de astros, de caballos y de personas. Poco antes de morir, descubre que ese paciente laberinto de líneas traza la imagen de su cara (BORGES, 854. El subrayado es mío).

Referências

Agamben, Giorgio. Homo Sacer. El poder soberano y la nuda vida. Valencia, Pre-Textos, 1998 [1995].

Antelo, Raúl. Para uma arqueologia do testemunho latino-americano. Conferencia, Leiden, febrero 2006.

Barthes, Roland. La chambre claire. Notes sur la photographie. Paris, Cahiers du Cinéma/Gallimard/Seuil, 2000 (1980)

Beaujour, Michel. Miroirs d'encre. Paris, Seuil (Coll. Poétique), 1980.

Borges, Jorge Luis. Obras Completas 1923-1972. Buenos Aires, Emecé Editores, 1974.

Caillois, Roger. La mante religieuse. Minotaure 5 (mai 1934). En Le mythe et I' homme, 39-99.

Mimétisme et psychasténie légendaire. Minotaure 7 (juin 1935). En Le mythe et l' homme, 100-143.

Le mythe et l'homme. Paris, Gallimard (Coll. Folio/essais 56), 1987 [1938].

Deleuze, Gilles. Francis Bacon. Logique de la sensation. Paris, Editions de la différence (Coll. La Vue le Texte), 2 vols., 1996 ( 4 a ed.).

Eco, Umberto. Pour une reformulation du concept de signe iconique. Communications 29, 1978, 141-191.

Kant et l'ornithorynque. Paris, Grasset (le livre de poche) 2001 [1997].

Mirrors. En Semiotics and the Philosophy of Language. Bloomington, Indiana University Press, 1986, 202-226.

Foucault, Michel. La pensée du dehors. Critique, 229, juin 1966 :523-546. En Dits et écrits I, 1954-1975. 546-557.

L'ordre du discours. Paris, Gallimard, 1979.

Surveiller et punir. Naissance de la prison. Paris, NRF/Gallimard, 1989 [1975].

Histoire de la sexualité 1. La volonté de savoir. Paris, NRF/Gallimard, 1976.

Dits et écrits I, Paris, Quarto Gallimard, 2001.

Hollier, Denis. Les Dépossédés (Bataille, Caillois, Leiris, Malraux, Sartre). Paris, Minuit, 1993.

Jay, Martin. Campos de fuerza. Entre la historia intelectual y la crítica cultural. Buenos Aires, Paidós, 2003 [1993].

Lejeune, Philippe. L'autobiographie en France. Paris, Armand Colin, 1971.

Lire Leiris : autobiographie et langage. Paris, Klincksiek, 1975.

Leiris, Michel. Aurora. Paris, Gallimard, 1946.

Montaigne, Michel de. Essais. Paris, Gallimard, Pléiade, 1962

Nancy, J ean-Luc. Le regard du portrait. Paris, Galilée, 2000.

Au fond des images. Paris, Galilée, 2005.

Olalquiaga, Ceste. Megalópolis. Caracas, Monte Avila Latinoamericana, 1991.

Peirce, Charles S. Collected Papers. Vol. I-VI, ed. Ch. Hasthorne y P.Weiss. Cambridge, Mass., Harvard University Press, 1958 [1931]. 
Rodríguez Carranza, L. Un teatro de la memoria. Análisis de Terra Nostra, de Carlos Fuentes. Leuven/Buenos Aires, Leuven University Press/Albero Vergara, 1991.

Updike, J. La azarosa vida de las biografías literarias.

http://www.clarin.com/suplementos/cultura/1999/03/28/03/28/e-00401d.htm consultado el 6-5-2006.

Van Gorp, R. e.a. Lexicon van Literaire Termen. 7vd. druk. Groningen/Deurne, Martinus Nijhoff/ Wolters Plantyn, 1998.

Yates, Frances A. The Art of Memory. London, Penguin, 1969

Žižek, Slavoj. El sublime objeto de la ideología. Buenos Aires, Siglo Veintiuno Editores, 2005 (1a ed., 1a reimp.) [1989].

Recebido em 05/06/07. Aprovado em 08/07/07.

Title: Lives without Stories. For a Semiotics of the Literary Self-portrait

Author: Luz Rodríguez Carranza

Abstract: The present work is a reflection on certain texts, which share many of the characteristics of the portrait, being their modern name "literary self-portrait." It is a very old genre, ignored and marginalized - or indiscriminately included with the essays-by the modern poetics, which holds Rousseau's Confessions as the ground zero for the writings on the self. In order to describe its peculiar mode of communication, here self-portraits are confronted with some concepts of the philosophy of the image (J ean-Luc Nancy), and of semiotics (Umberto Eco).

Keywords: literary life; tracks; voice; memory; autobiography.

Tìtre: Vies sans histoires. Pour une sémiotique de l'autoportrait littéraire

Auteur: Luz Rodríguez Carranza

Résumé: Ce travail est une réflexion sur certains textes qui partagent plusieurs caractéristiques des portraits, et sa désignation moderne est "autoportrait littéraire". II s'agit d'un genre très ancien, ignoré et marginalisé - ou inclus indistinctement parmi les essais - par les poétiques modernes, qui ont dans Les Confessions de Rousseau le point de départ absolu des écritures du moi. Pour décrire sa manière particulière de communiquer, les autoportraits sont opposés ici avec quelques notions de la philosophie de l'image (Jean-Luc Nancy) et de la sémiotique (Umberto Eco)

Mots-clés: vie littéraire; traces; voix; mémoire; autobiographie.

Título: Vidas sem histórias. Por uma semiótica do auto-retrato literário

Autor: Luz Rodríguez Carranza

Resumo: Este trabalho é uma reflexão sobre certos textos que compartilham muitas das características dos retratos, sendo que seu nome moderno é o de "auto-retrato literário". Trata-se de um gênero muito antigo, ignorado e marginalizado - ou incluído indiscriminadamente entre os ensaios - pelas poéticas modernas, que têm nas Confissões de Rousseau o ponto de partida absoluto das escrituras do eu. Para descrever seu modo peculiar de comunicar, os auto-retratos são confrontados aqui com alguns conceitos da filosofia da imagem (J ean-Luc Nancy) e da semiótica (Umberto Eco)

Palavras-chave: vida literária; rastros; voz; memória; autobiografia.

[1] www.ediciones-omega.es Consultado el 2-05-06

[2] www.eud.com/verbigracia/memoria/N207/central3.shtml. Consultado el 2-05-06

[3] Es obvio que sin Lacan y Derrida, y sin la recuperación de Warburg y Yates por Michaud y Didi Huberman (en mi caso por Carlos Fuentes) los «teatros de la memoria » tampoco hubieran sido visibles.

[4] Refiero aquí, desde luego, al concepto de sicastenia de Caillois, citado frecuentemente por Raúl Antelo. Ver también Olalquiaga, a quien la sicastenia le resulta políticamente peligrosa, 23 .

[5] Ambas, filosofía y semiótica, en realidad, lo que aceptaron fue el psicoanálisis, como el resto de las ciencias humanas. Esta cita de Eco lo demuestra con creces. En 1989 Žižek adopta la teoría de los nombres propios de Kripke, privándola de su esencialismo, para explicar el efecto retroactivo de la nominación como positivación del deseo.

[6] Los subrayados son de Eco y corresponden a definiciones de funciones semióticas que son explicadas posteriormente.

[7] Michel Beaujour señala que las Confesiones de San Agustín, la obra de Francis Bacon o los Ensayos de Montaigne revelan la incompatibilidad entre la aparición del lenguaje y la conciencia de sí y la identidad mucho antes de la formulación del cogito cartesiano (18). [8] Beaujour (31-21) habla de «speculum mundi», y su libro se llama Miroirs d'encre (Espejos de tinta). Yo prefiero evitar los espejos, que son abominables no sólo porque reproducen, sino porque sólo lo hacen in praesentia (cf. ECO, Mirrors) y no son impresionables, no guardan huellas.

[9] El Passagenwerk tiene muchas semejanzas con Mnemosyne, y el método historiográfico de Benjamin - el salto del tigre de la $n^{0}$ XIV de las Tesis de Filosofía de la Historia - es, a mi juicio, también el método del autorretratista. Pero eso es tema de otro trabajo. [10] Laberintos y bibliotecas también, claro está.

[11] Pablo Oyarzun, en una conversación conmigo en Leiden sobre otro tema, ejemplificó esta perversidad con Google : «un 'menú' limitado que alimenta la ilusión de controlar una multiplicación ilimitada».

\footnotetext{
* Professora Dra. da Universiteit Leiden.
}

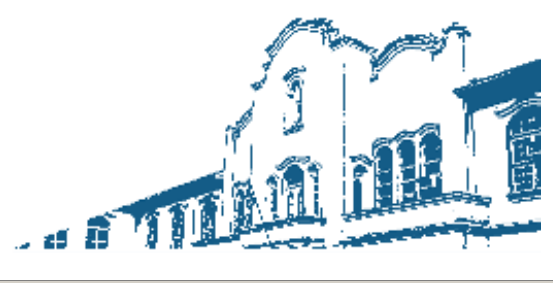

Copyright PPGCL/ Unisul 2006 @ (48) 3621-3369 - Desenvolvimento: Prof. Dr. Fábio J osé Rauen 